\title{
Beneficial effect of combination therapy with mitiglinide and voglibose on fasting and postprandial endothelial dysfunction in patients with type 2 diabetes: a pilot study
}

Masanori Murakami ${ }^{1}$, Ryotaro Bouchi ${ }^{*}$, Norihiko Ohara ${ }^{1}$, Tatsuya Fukuda ${ }^{1}$, Takato Takeuchi ${ }^{1}$, Isao Minami ${ }^{1}$, Koshi Hashimoto ${ }^{1,2}$ Takanobu Yoshimoto ${ }^{1}$ and Yoshihiro Ogawa ${ }^{1,3}$

${ }^{1}$ Department of Molecular Endocrinology and Metabolism, Graduate School of Medical and Dental Sciences, Tokyo Medical and Dental University, Tokyo, Japan ${ }^{2}$ Department of Preemptive Medicine and Metabolism, Graduate School of Medical and Dental Sciences, Tokyo Medical and Dental University; ${ }^{3}$ CREST, Japan Agency for Medical Research and Development, Tokyo, Japan

\begin{abstract}
Objective: This study was to investigate whether switching sulfonylurea to mitiglinide/voglibose could improve glycemic variability and endothelial dysfunction in patients with type 2 diabetes.

Methods: This was a single arm study of 6 Japanese patients with type 2 diabetes ( $n=6,5$ male, $72 \pm 7$ year-old). Patients with $0.25-1.0 \mathrm{mg}$ of glimepiride (0.8 \pm 0.3 $\mathrm{mg}$ ) with $\mathrm{HbA} 1 \mathrm{c}$ between $6.5-7.5 \%$ were enrolled and were switched from glimepiride to mitiglinide/voglibose (fixed-dose combination of mitiglinide $10 \mathrm{mg}$ and voglibose $0.2 \mathrm{mg}$ three times a day) for 3 months.

Results: Mean amplitude of glycemic excursion (MAGE) was significantly decreased from $3.4 \pm 1.3$ to $1.6 \pm 0.6 \mathrm{mmol} / 1(P=0.014)$. Both fasting and postprandial FMD also significantly improved $(5.3 \pm 1.6$ vs. $7.1 \pm 1.7, P=0.043$ and $3.5 \pm 1.5$ vs. $5.2 \pm 1.1, P=0.043)$. The declines of insulin and $\mathrm{C}$-peptide levels at 120 min were significantly correlated with the increase in postprandial FMD $(r=-0.97, P=0.013$, and $r=-1.00, P=0.004)$.

Conclusions: Glycemic variability and endothelial dysfunction at fasting and postprandial states were improved by mitiglinide/voglibose and it may be through the attenuation of hyperinsulinemia.
\end{abstract}

\section{Introduction}

Sulfonylurea (SU) is recommended as one of the second-line drugs in patients with type 2 diabetes if HbAlc target is not achieved after $\sim 3$ months of metformin monotherapy [1]. Long-term, prospective randomized clinical trials, such as the UK Prospective Diabetes Study (UKPDS) [2], have demonstrated the fundamental role of intensive glycemic control in reducing the microvascular complications. Treatment with SUs has remained the main pharmacologic approach for the treatment of type 2 diabetes for many decades because of their reliable efficacy. However, in spite of the extensive use, recommendations in guidelines, and pathophysiologic plausibility, concern has grown over the past decade with respect to SU therapy. Patients treated with SU are more likely to have severe hypoglycemic episodes [3] and weight gain than those with other second-line drugs such as dipeptidyl peptidase 4 (DPP4) inhibitors $[4,5]$.

Mitiglinide/voglibose fixed-dose combination is a drug combining a short-acting insulin secretagogue (glinide) and a postprandial hyperglycemia-improving agent ( $\alpha$-glucosidase inhibitor), which inhibit carbohydrate absorption and reduce post-prandial hyperglycemia without stimulating insulin secretion [6]. It is known that intervention with a-glucosidase inhibitor prevented cardiovascular disease [7] and glinide appeared to be associated with a lower cardiovascular risk than SU in patients with type 2 diabetes [8], however, they are not located on the second-line drug due to their limited evidences.
We focused on the potential of the combination treatment to ameliorate endothelial dysfunction due to reducing the postprandial hyperglycemia $[9,10]$, because previous studies showed that each monotherapy of glinide and a-glucosidase inhibitor ameliorated endothelial dysfunction $[11,12]$. In this context, we conducted this pilot study to investigate whether switching from SU to mitiglinide/ voglibose could reduce the fluctuation of blood glucose, eventually decreasing in the hypoglycemic episodes and amelioration of endothelial dysfunction in patients with type 2 diabetes.

\section{Subjects and methods}

Patients with less than $1.0 \mathrm{mg}$ of glimepiride $(0.8 \pm 0.3 \mathrm{mg})$ with $\mathrm{HbAlc}$ between $6.5-7.5 \%$ ( $n=6,5$ male, $72 \pm 7$ year-old) were enrolled. Two patients were treated with metformin and 1 patient with vildagliptin at the base line. The patients were switched from glimepiride to mitiglinide/voglibose (fixed-dose combination of mitiglinide $10 \mathrm{mg}$

Correspondence to: Ryotaro Bouchi, Department of Molecular Endocrinology and Metabolism, Graduate School of Medical and Dental Sciences, Tokyo Medical and Dental University, 1-5-45 Yushima, Bunkyo-ku, Tokyo 113-8510, Japan, Tel: +81-3-5803-5216; Fax: +81-3-5803-0172; E-mail: bouchi.mem@tmd.ac.jp

Key words: Glinide, $\alpha$-glucosidase inhibitor, endothelial dysfunction

Received: December 22, 2016; Accepted: January 07, 2017; Published: January 10,2017 
Murakami M (2017) Beneficial effect of combination therapy with mitiglinide and voglibose on fasting and postprandial endothelial dysfunction in patients with type2 diabetes: a pilot study

and voglibose $0.2 \mathrm{mg}$ three times a day) for 3 months.

Mean amplitude of glycemic excursion (MAGE) and hypoglycemic episodes were determined by continuous glucose monitoring (CGM) for 5 patients. Hyperglycemia and hypoglycemia were defined as glucose levels above $10.0 \mathrm{mmol} / \mathrm{l}$ and below $3.9 \mathrm{mmol} / \mathrm{l}$ and time in hyperglycemia and hypoglycemia were determined by CGM. Endothelial function was assessed by flow-mediated vasodilation (FMD) at fasting and 2 hours after meal tolerance test $(592 \mathrm{kcal}$, SARAYA Corp, Osaka, Japan) using a high-resolution ultrasound method for 5 patients $[13,14]$. Glucose, insulin and C-peptide levels were also determined at baseline, $60 \mathrm{~min}$ and $120 \mathrm{~min}$ in meal tolerance test.

Statistical analysis was carried out using programs available in the spss version 21.0 statistical package (SPSS Inc., Chicago, IL, USA). Data are presented as mean \pm standard deviation. Patients characteristics and average of $24-\mathrm{hr}$ glycemic variations were analyzed with paired t-test. Changes in FMD were analyzed with Wilcoxon signed-rank test. Correlation between $\Delta \mathrm{C}$-peptide or $\Delta$ insulin and $\triangle \mathrm{FMD}$ were evaluated with Pearson's correlation coefficient. Differences were considered to be statistically significant at a $P$ value $<0.05$.

\section{Results}

MAGE was significantly reduced from $3.4 \pm 1.3$ to $1.6 \pm 0.6 \mathrm{mmol} / \mathrm{l}$ $(P=0.014)$ with the trend for reduction of time in hypoglycemic range (2.3 vs. $0.3 \%, P=0.176)$ and in hyperglycemic range $(22.4 v s .11 .8 \%, P$

Table 1. Patient profiles before and after switching from glimepiride to mitiglinide/ voglibose.

\begin{tabular}{|l|l|l|l|}
\hline & Glimepiride & Mitiglinide/Voglibose & $P$ value \\
\hline BMI $\left(\mathrm{kg} / \mathrm{m}^{2}\right)$ & $23.6 \pm 4.7$ & $23.1 \pm 4.2$ & 0.258 \\
\hline SBP $(\mathrm{mmHg})$ & $131.7 \pm 23.9$ & $129.2 \pm 23.4$ & 0.665 \\
\hline DBP $(\mathrm{mmHg})$ & $79.2 \pm 16.1$ & $83.5 \pm 13.2$ & 0.202 \\
\hline HR (b.p.m.) & $81.8 \pm 28.5$ & $76.8 \pm 13.3$ & 0.503 \\
\hline FPG (mmol/l) & $6.6 \pm 0.8$ & $7.5 \pm 0.8$ & 0.005 \\
\hline HbA1c (\%) & $7.1 \pm 0.3$ & $7.1 \pm 0.8$ & 1.000 \\
\hline AST (IU/l) & $18.2 \pm 5.0$ & $20.0 \pm 10.6$ & 0.658 \\
\hline ALT (IU/l) & $20.3 \pm 14.2$ & $23.5 \pm 17.4$ & 0.637 \\
\hline$\gamma$-GTP (IU/l) & $41.2 \pm 35.7$ & $40.0 \pm 36.3$ & 0.666 \\
\hline TG (mmol/l) & $1.2 \pm 0.5$ & $1.1 \pm 0.6$ & 0.683 \\
\hline HDL Chol (mmol/l) & $1.4 \pm 0.3$ & $1.4 \pm 0.4$ & 0.907 \\
\hline LDL Chol (mmol/l) & $2.2 \pm 0.3$ & $2.3 \pm 0.5$ & 0.593 \\
\hline UACR (mg/g) & $60.1 \pm 113.6$ & $70.7 \pm 118.6$ & 0.140 \\
\hline
\end{tabular}

Data are expressed as number or mean $\pm \mathrm{SD}$. $P$ values were calculated with paired t-test Abbreviations: BMI: body mass index, SBP: systolic blood pressure, DBP: diastolic blood pressure, HR: heart rate, FPG: fasting plasma glucose, AST: aspartate aminotransferase, ALT; alanine transaminase, $\gamma$-GTP: $\gamma$-glutamyltransferase, TG: triglycerides, HDL Chol high-density lipoprotein cholesterol, LDL Chol: low-density lipoprotein cholesterol, UACR: urinary albumin-to-creatinine ratio.

Table 2. Results of continuous glucose monitoring.

\begin{tabular}{|c|c|c|c|c|c|c|c|c|}
\hline & Case & 1 & 2 & 3 & 4 & 5 & Average & P value \\
\hline Mean \pm SD & Glimepiride & $9.5 \pm 1.7$ & $7.9 \pm 2.3$ & $7.6 \pm 1.4$ & $8.7 \pm 2.0$ & $6.9 \pm 1.2$ & $8.1 \pm 1.2$ & \multirow{2}{*}{0.500} \\
\hline$(\mathrm{mmol} / \mathrm{l})$ & Mit/Vog & $8.9 \pm 1.1$ & $8.1 \pm 1.3$ & $6.7 \pm 1.0$ & $8.6 \pm 1.4$ & $7.3 \pm 1.0$ & $7.9 \pm 0.7$ & \\
\hline $\mathrm{MAGE} \pm \mathrm{SD}$ & Glimepiride & $3.7 \pm 2.0$ & $4.8 \pm 1.9$ & $4.3 \pm 1.3$ & $6.6 \pm 2.0$ & $3.6 \pm 1.4$ & $3.4 \pm 1.3$ & \multirow{2}{*}{0.014} \\
\hline$(\mathrm{mmol} / \mathrm{l})$ & Mit/Vog & $2.4 \pm 1.3$ & $2.8 \pm 1.1$ & $2.0 \pm 0.9$ & $4.1 \pm 0.8$ & $2.2 \pm 1.1$ & $1.6 \pm 0.6$ & \\
\hline Hypoglycemia & Glimepiride & 0.0 & 4.9 & 0.0 & 4.3 & 2.1 & $2.3 \pm 2.3$ & \multirow{2}{*}{0.176} \\
\hline$(\%)$ & Mit/Vog & 0.0 & 0.4 & 1.4 & 0.0 & 0.0 & $0.3 \pm 0.6$ & \\
\hline Hyperglycemia & Glimepiride & 37.9 & 20.9 & 10.1 & 36.5 & 6.6 & $22.4 \pm 14.5$ & \multirow{2}{*}{0.167} \\
\hline$(\%)$ & Mit/Vog & 25.8 & 23.4 & 2.1 & 2.9 & 4.9 & $11.8 \pm 11.8$ & \\
\hline
\end{tabular}

Mean glucose and mean amplitude of glycemic excursion (MAGE) levels in 24-hr continuous glucose monitoring were expressed with standard deviation (SD) in each case with glimepiride or mitiglinide/voglibose (Mit/Vog). Hypoglycemic and hyperglycemic episodes were expressed as ratios of time exposed under 3.9 mmol/l and above 10.0 mmol/1, respectively. $P$ values were calculated with paired t-test.
$=0.167)$; whereas, 24 -hour mean glucose $(8.1$ vs. $7.6 \mathrm{mmol} / \mathrm{l}, P=0.500)$ and HbAlc (7.1\% vs. $7.1 \%, P=1.000)$ levels were unchanged (Tables 1 and 2) (Figure 1). Both fasting and postprandial FMD significantly improved $(5.3 \pm 1.6$ vs. $7.1 \pm 1.7, P=0.043$ and $3.5 \pm 1.5$ vs. $5.2 \pm 1.1, P$ $=0.043$, respectively) (Figure $2 \mathrm{~A}$ ). There were trends for lower glucose (13.5 vs. $11.3 \mathrm{mmol} / \mathrm{l}, P=0.111$ ), insulin (44.6 vs. $22.8 \mu \mathrm{U} / \mathrm{ml}, P=$ 0.183 ), and C-peptide (7.vs. $34.9 \mathrm{ng} / \mathrm{ml}, P=0.164$ ) levels at $120 \mathrm{~min}$ in meal tolerance test after switching to mitiglinide/voglibose. Clinical parameters including body mass index, blood pressure, transaminases, lipid profile and albuminuria did not change after switching to mitiglinide/voglibose. Our analysis showed that both the declines of insulin and C-peptide levels at $120 \mathrm{~min}$ were significantly correlated with the increase in postprandial FMD $(r=-0.97, P=0.013$, and $r=$ $-1.00, P=0.004$, respectively) (Figure $2 \mathrm{~B}$ and $2 \mathrm{C}$ ).

\section{Discussion}

In this study, MAGE and the time in hypoglycemic episodes were significantly decreased and endothelial dysfunction at fasting and postprandial states were improved after switching SU to mitiglinide/ voglibose in patients with type 2 diabetes. Further, meal tolerance test showed significant relationships between the attenuation of hyperinsulinemia and the improvement of endothelial dysfunction. The hyperinsulinemic responses to glucose are markedly exaggerated in the patients with SU and they are responsible for hypoglycemic episodes and endothelial dysfunction [15]. It is of note that our patients were all older than 65 years old. Elderly patients with diabetes, especially those with SU are at high risk for hypoglycemia [16]. The significant reduction of time in hypoglycemic episodes with unchanged

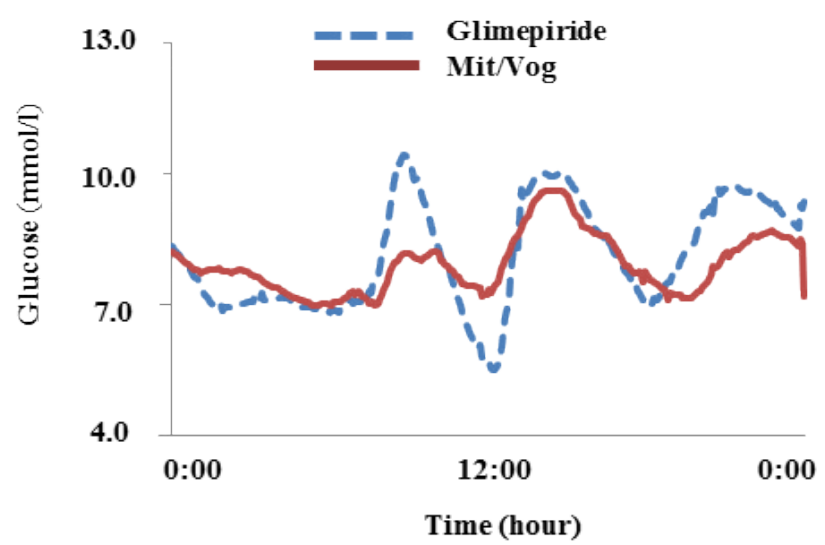

Figure 1. Average of 24-hr glycemic variations in 5 patients. Dashed blue line means glycemic variations in patients with glimepiride and solid red line means those in patients with mitiglinide/voglibose (Mit/Vog). 
Murakami M (2017) Beneficial effect of combination therapy with mitiglinide and voglibose on fasting and postprandial endothelial dysfunction in patients with type2 diabetes: a pilot study

B

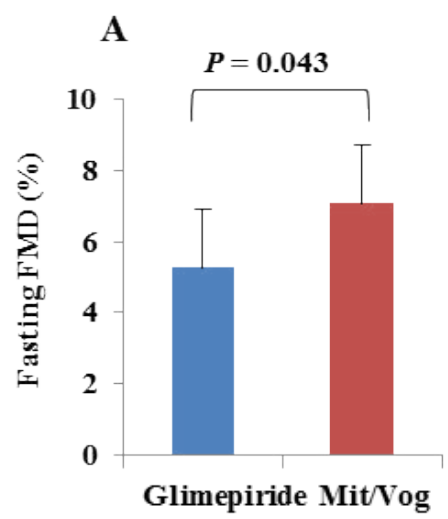

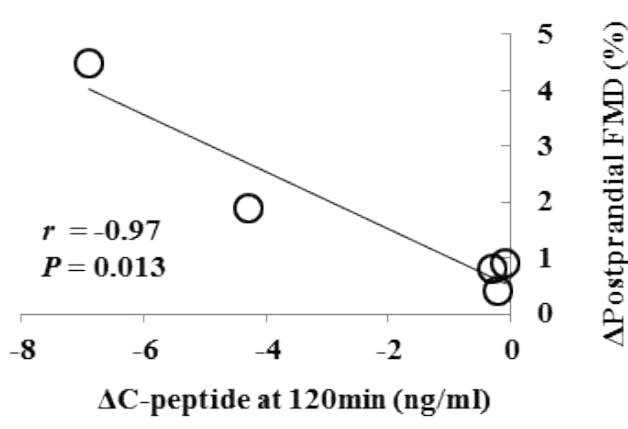

C

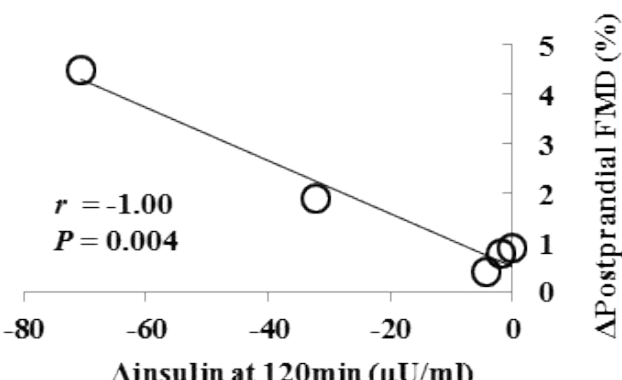

Figure 2. A. Changes in flow-mediated vasodilation (FMD) with glimepiride or mitiglinide/voglibose (Mit/Vog) at fasting and 120 min after meal tolerance test (postprandial) in 5 patients Blue bars mean ( \pm standard deviation) FMD with glimepiride and red bars mean that with Mit/Vog. P values were calculated with Wilcoxon signed-rank test. Differences were considered to be statistically significant at a $\mathrm{P}$ value $<0.05$. B, C. Correlation between $\Delta \mathrm{C}$-peptide (B) or $\Delta$ insulin (C) at 120 min and $\Delta \mathrm{FMD}$ at 120 min after meal tolerance test (postprandial) in 5 patients. Correlations were evaluated with Pearson's correlation coefficient. Differences were considered to be statistically significant at a $\mathrm{P}$ value $<0.05$.

HbA1c by mitiglinide/voglibose in this study suggests the possibility that improvement in quality of glycemic control can be achieved by switching from SU to mitiglinide/voglibose in elderly patients with type 2 diabetes. Moreover, considering the fact that hypoglycemic episodes sometimes result in a fatal cardiovascular outcome [17] and endothelial dysfunction causes the progression of microvascular complication in patients with diabetes [18], it is also possible that mitiglinide/voglibose could be alternative for SU in order to improve endothelial dysfunction and prevent future micro- and macrovascular diabetic complications.

\section{Conclusion}

We showed the beneficial effects of mitiglinide/voglibose in the point of glycemic variability and endothelial function in patients with type 2 diabetes. There is the possibility that mitiglinide/voglibose is located on the second-line for treatment of type 2 diabetes.

\section{Acknowledgment}

The authors thank all of the other staff members of the Molecular Endocrinology and Metabolism Department at Tokyo Medical and Dental University.

\section{Funding}

This study was supported in part by Grants-in-Aid for Scientific Research from the Ministry of Education, Science, Sports and Culture of Japan.

\section{References}

1. American Diabetes Association (2016) Standards of Medical Care in Diabetes-2016 Abridged for Primary Care Providers. Clin Diabetes 34: 3-21. [Crossref]

2. UKPDS-Group (1998) Intensive blood-glucose control with sulphonylureas or insulin compared with conventional treatment and risk of complications in patients with type 2 diabetes (UKPDS 33). Lancet 352: 837-853. [Crossref]
3. Haneda M, Morikawa A (2009) Which hypoglycaemic agents to use in type 2 diabetic subjects with CKD and how? Nephrol Dial Transplant 24: 338-341. [Crossref]

4. Seck T, Nauck M, Sheng D, Sunga S, Davies MJ, et al. (2010) Safety and efficacy of treatment with sitagliptin or glipizide in patients with type 2 diabetes inadequately controlled on metformin: a 2-year study. Int J Clin Pract 64: 562-576. [Crossref]

5. Nauck MA1, Meininger G, Sheng D, Terranella L, Stein PP, et al. (2007) Efficacy and safety of the dipeptidyl peptidase-4 inhibitor, sitagliptin, compared with the sulfonylurea, glipizide, in patients with type 2 diabetes inadequately controlled on metformin alone: a randomized, double-blind, non-inferiority trial. Diabetes Obes Metab 9: 194-205. [Crossref]

6. Inoue M (2012) Tighter control of postprandial hyperglycemia with mitiglinide voglibose fixed-dose combination in Japanese patients with type 2 diabetes mellitus. Expert Opin Pharmacother 13: 2257-2268. [Crossref]

7. Hanefeld M, Cagatay M, Petrowitsch T, Neuser D, Petzinna D, et al. (2004) Acarbose reduces the risk for myocardial infarction in type 2 diabetic patients: meta-analysis of seven long-term studies. Eur Heart J 25: 10-16.

8. Schramm TK, Gislason GH, Vaag A, Rasmussen JN, Folke F, et al. (2011) Mortality and cardiovascular risk associated with different insulin secretagogues compared with metformin in type 2 diabetes, with or without a previous myocardial infarction: a nationwide study: Eur Heart J 32: 1900-1908. [Crossref]

9. Ono Y, Kameda H, Cho KY (2013) Mitiglinide/voglibose fixed-dose combination improves postprandial glycemic excursions in Japanese patients with type 2 diabetes mellitus. Expert Opin Pharmacother 14: 361-370.

10. Suzuki K, Watanabe K, Futami-Suda S, Yano H, Motoyama M, et al. (2012) The effects of postprandial glucose and insulin levels on postprandial endothelial function in subjects with normal glucose tolerance. Cardiovasc Diabetol 11: 98. [Crossref]

11. Manzella D, Grella R, Abbatecola AM, Paolisso G (2005) Repaglinide administration improves brachial reactivity in type 2 diabetic patients. Diabetes Care 28: 366-371. [Crossref]

12. Sawada T, Shiotani H, Terashita D, Nagasawa Y, Kim SS, et al. (2014) Comparison of effects of alpha-Glucosidase inhibitors and glinide drugs on endothelial dysfunction in diabetic patients with coronary artery disease. Circ J 78: 248-255. [Crossref]

13. Celermajer DS, Sorensen KE, Gooch VM, Spiegelhalter DJ, Miller OI, et al. (1992) Non-invasive detection of endothelial dysfunction in children and adults at risk of atherosclerosis. Lancet 340: 1111-1115. [Crossref] 
Murakami M (2017) Beneficial effect of combination therapy with mitiglinide and voglibose on fasting and postprandial endothelial dysfunction in patients with type2 diabetes: a pilot study

14. Kawano H, Motoyama T, Hirashima O, Hirai N, Miyao Y, et al. (1999) Hyperglycemia rapidly suppresses flow-mediated endothelium-dependent vasodilation of brachial artery. J Am Coll Cardiol 34: 146-154. [Crossref]

15. Del Prato S, Pulizzi N (2006) The place of sulfonylureas in the therapy for type 2 diabetes mellitus. Metabolism 55(5 Suppl 1): S20-27. [Crossref]

16. Deusenberry CM, Coley KC, Korytkowski MT, Donihi AC (2012) Hypoglycemia in hospitalized patients treated with sulfonylureas. Pharmacotherapy 32: 613-617. [Crossref]

17. Goto A, Arah OA, Goto M, Terauchi Y, Noda M (2013) Severe hypoglycaemia and cardiovascular disease: systematic review and meta-analysis with bias analysis. $B M J$ 347: f4533. [Crossref]

18. Tousoulis D, Kampoli AM, Stefanadis C (2012) Diabetes mellitus and vascular endothelial dysfunction: current perspectives. Curr Vasc Pharmacol 10: 19-32. [Crossref]

Copyright: (C2016 Murakami M. This is an open-access article distributed under the terms of the Creative Commons Attribution License, which permits unrestricted use, distribution, and reproduction in any medium, provided the original author and source are credited. 